\title{
Bio-based High Performance Epoxy-Anhydride Thermosets for Structural Composites: The Effect of Composition Variables
}

\author{
Adlina Paramarta and Dean C. Webster ${ }^{1}$ \\ Department of Coatings and Polymeric Materials \\ North Dakota State University \\ Fargo, ND USA- 58108
}

\begin{abstract}
The structure-property relationships of a designed series of anhydride-cured epoxidized sucrose soyate (ESS) thermosets were studied. Epoxidized sucrose soyate is a novel bio-based epoxy resin derived from sucrose and soybean oil fatty acids, and it contains an average of 12 epoxy functional groups per molecule. This epoxy resin was crosslinked with methyl hexahydrophthalic anhydride to form polyester thermosets with high crosslink density, and a zinc-complex catalyst was used. In this study, the impact of composition variables-anhydrideto-epoxy molar ratio and catalyst amount —on the chemical, mechanical, and thermal properties of the thermosets were examined. All of the thermoset samples had very high gel fraction, which indicated excellent network connectivity. Samples made using an equimolar ratio of anhydrideto-epoxy groups had lower conversion of functional groups as shown by the somewhat lower gel fraction and higher moisture absorption. Analysis of the thermomechanical and tensile properties of the thermosets suggests that there is a factor interaction between anhydride-toepoxy molar ratio and catalyst amount. Furthermore, the results suggest that the molecular networks of the thermoset samples are fairly complex due to the simultaneous competing reactions between catalyst-initiated epoxy-anhydride, hydroxyl- initiated epoxy-anhydride, and epoxy homopolymerization.
\end{abstract}

Keywords: epoxidized sucrose soyate, anhydride-cured epoxy, structure-property relationships, bio-based thermoset

\footnotetext{
${ }^{1}$ Corresponding author: PO Box 6050, Dept. 2760, Fargo, ND 58108; email: dean.webster@ndsu.edu; Ph: 701-2318709; Fax: 701-231-8439
} 


\section{Introduction}

In the recent decade, due to the uncertainty of the cost and supply of petrochemicals, more and more research has been devoted to the development of vegetable oils as a chemical commodity [1-6]. Vegetable oils offer promising potential in replacing petrochemicals in some applications due to their relatively low cost, abundant availability, and greater sustainability. The use of vegetable oils as a chemical commodity is in fact not a new concept. Vegetable oils such as linseed oil, tung oil, and soybean oil have been used for centuries in paints and coatings applications, such as in artist's paints, architectural paints and varnishes. The application of these vegetable oils as coatings binders still exists today. Currently, about 17 million tons of vegetable oils go toward the synthesis of chemicals and materials; this is about $15 \%$ by weight of the total annual production of vegetable oils, and the value is estimated to grow at about $3.3 \%$ per year [7, 8]. Furthermore, the use of vegetable oils has been broadened to many more fields, such as biofuels, lubricants, surfactants, and structural composites [1].

Chemically, vegetable oils are the triglycerides or glycerol esters of fatty acids. Vegetable oils from different plant sources contain unique fatty acids compositions, with many vegetable oils containing a significant fraction of unsaturated fatty acids. Polymerization of vegetable oils is possible through the unsaturation in the fatty acid chains, and the degree of unsaturation dictates the reactivity of a particular vegetable oil. The unsaturation can lead to polymerization through auto-oxidation using metal catalysts [9]. However, this crosslinking route often takes an extensive period of time for the materials to fully cure. One popular modification of vegetable oils is the epoxidation of the double bonds, which then provides access to many crosslinking technologies, such as epoxy homo-polymerization and copolymerization with amines or

acid/anhydrides. Furthermore, the epoxy functionality can be ring opened with acids or alcohols to introduce other functional groups. For example, epoxy groups can be reacted with acrylic or methacrylic acid to provide terminal double bond functionality, which can then be polymerized under ultra-violet light and/or thermal exposure to form crosslinked materials [10-13]. In addition, epoxy groups may be reacted with alcohol to introduce hydroxyl functional groups, which then can be crosslinked with either isocyanates to produce polyurethanes or with melamine formaldehyde resins [7, 8, 14-17].

As mentioned before, epoxy groups can be polymerized through crosslinking with either amines or acid/anhydride groups. Between these two potential crosslinkers, the acid/anhydride 
hardener is the main curing agent used for epoxidized vegetable oils for two reasons. First, epoxy groups in the fatty acids are internal epoxides, and thus they are less reactive compared to terminal epoxides. This low reactivity leads to low polymerization efficiency when crosslinked with amine hardeners. Second, during the reaction between epoxidized vegetable oils with amine hardeners, there is possibility of de-esterification of the fatty acid chain through an esteraminolysis reaction to form amide bonds and alcohols as a by-product [18].

The reaction of epoxides and anhydrides are known to be complex due to many simultaneous reactions. The reaction can undergo both catalyzed and non-catalyzed processes. An uncatalyzed reaction pathway may be possible due to the presence of hydroxyl groups on the epoxy resins or from impurities in the raw materials. However, in most cases, the use of catalyst is necessary to ensure an efficient polymerization [19-22]. Catalysis of epoxy-anhydride reactions is often performed with Lewis base catalysts such as tertiary amines, amidines, quaternary onium salts, or metal salts. These catalysts initiate the polymerization reaction through nucleophilic attack on the epoxy and/or anhydride, and then form a zwitterionic alkoxide and/or carboxylate anion [23]. These anions then become the active group and propagate the polymer chain by further reaction with anhydride and/or epoxy groups. Scheme 1 illustrates the two reaction mechanisms. The difference between these mechanisms lies in the initiation mechanism and active end group of the polyester chain. For both mechanisms, the propagation reactions have been suggested to occur in an alternating fashion, therefore the bulk of the thermoset should contain polyester linkages. However, the polyetherification side reaction is possible due to homopolymerization of epoxy groups; the extent of polyetherification that occurs depends on the type and amount of catalyst used in the curing formulation. 


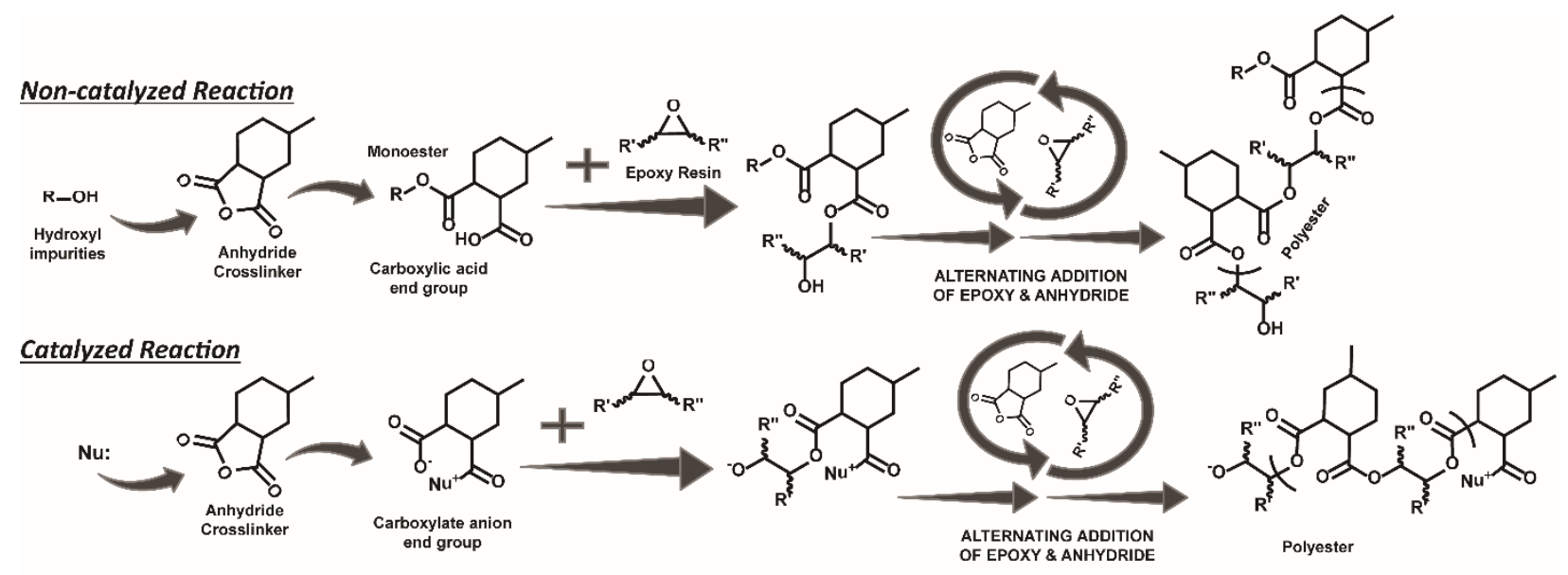

Polyetherification Side Reaction

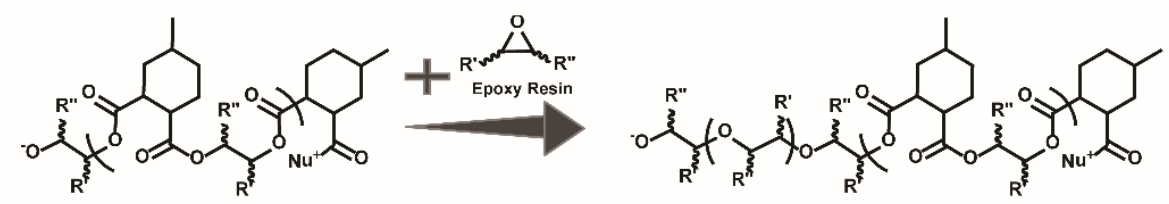

Scheme 1. Reaction mechanism of epoxy and anhydride curing

In the recent decade, there has been extensive research dedicated to the development of fiber reinforced polymer (FRP) composites using bio-based thermosets as the matrix resin [24-29]. For an application intended for structural parts that requires high performance properties, it is necessary that the thermoset has high crosslink density and glass transition temperature $\left(T_{g}\right)$ so that it can efficiently transfer and distribute stress amongst the reinforcement without the initiation of cracks [30]. Unfortunately, most of the thermosets based on anhydride-cured epoxidized vegetable oils (EVOs) generally have low crosslink density and $T_{g}$. Therefore, FRP composites based on pure anhydride-cured EVOs are typically employed for situations that do not require high performance [31-33]. For use in structural FRP composites, EVOs are often blended with petrochemical-based epoxy resins such as the diglycidyl ether of bisphenol A (DGEBA) to enhance the strength and toughness of the final product $[30,34]$. In spite of this, the amount of DGEBA added to EVO must be carefully considered to ensure achieving optimum curing time, modulus, $T_{g}$, thermal stability, and chemical resistance. Often, DGEBA resin is used at concentrations of $>60 \%$ of total weight, so that the final thermoset has comparable properties to the neat DGEBA polymers. Yet, at this concentration, the final product would have significantly lower bio-based content.

An improved bio-based epoxy resin derived from vegetable oil has recently been developed [35]. This epoxy resin is named epoxidized sucrose ester (ESE), and a representative chemical 
structure is shown in Figure 1. ESE resins are made by esterifying vegetable oil fatty acids onto the hydroxyl groups of sucrose, followed by epoxidation of the double bonds. Thermosets based on ESEs have significantly higher strength and $T_{g}$ compared to EVO-based materials [36]. The improvement in the mechanical properties has been attributed to the rigidity of the sucrose core and the higher crosslink density due to more epoxy functional groups per molecule [36]. The number of the epoxy groups in the ESE depends on the type of fatty acids in the molecule. Anhydride-cured thermosets based on ESE have been shown to have good mechanical properties for coatings applications $[24,37]$. Based on this result, therefore, the thermoset has excellent potential to be used as a matrix resin for FRP composites. Furthermore, in order to be able to achieve the best possible properties, it is important to understand the effect of composition variables of the matrix resin itself on the thermoset properties.

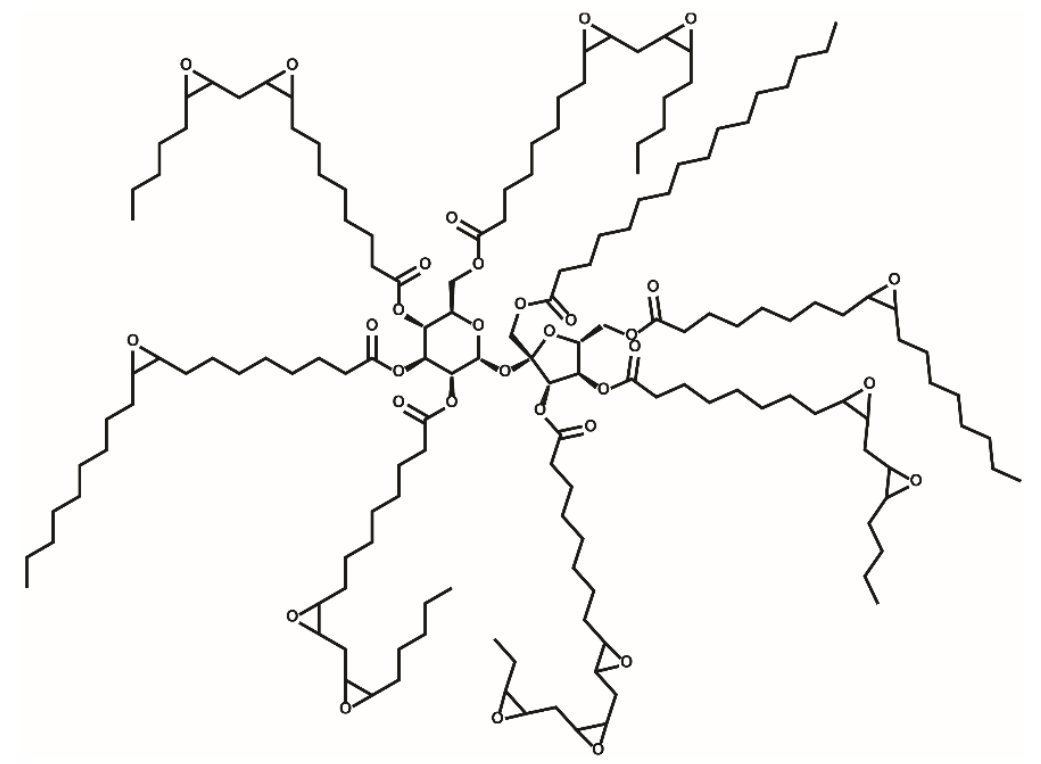

\section{Figure 1. Representative chemical structure of epoxidized sucrose ester}

In this study, the properties of anhydride-cured epoxidized sucrose soyate (ESS) are explored as a function of its composition variables, i.e. anhydride-to-epoxy equivalent ratio and catalyst amount. A good understanding of the structure-property relationships is critical when designing FRP composites for various applications. The properties assessed include sol/gel fraction, $T_{g}$ and crosslink density, tensile properties, and moisture uptake.

\section{Experimental}

2.1.Materials, polymer composition, and cure procedure 
Epoxidized sucrose soyate (ESS) was synthesized from sucrose soyate through the Prilezhaev reaction [35, 38]. The epoxy equivalent weight of the ESS resin was analyzed through hydrogen bromide titration, and the value was determined to be $250 \mathrm{~g} / \mathrm{mol}$. A liquid aliphatic anhydride, methyl hexahydrophthalic anhydride (MHHPA), was chosen as the crosslinker in this study; it was provided by Dixie Chemicals. The zinc-complex catalyst, CXC$1765 ®$, was provided by King Industries. The thermoset polymer composition was varied based on the anhydride-to-epoxy (AE) molar ratio and the catalyst amount. The AE molar ratio was chosen to be $0.5,0.75$, and 1.0 , while the catalyst amount was chosen to be 2,5 , and $8 \%$ of total weight of ESS and MHHPA; therefore, there is a total of nine formulations. The composition of these nine formulations is listed in Table 1.

To prepare the thermosets, first, ESS and MHHPA were mixed at $50{ }^{\circ} \mathrm{C}$ for 1 hour. Then, the catalyst was added gradually to the mixture over a 1-hour period. The epoxy-anhydride formulation mixtures were cured in a Teflon mold sandwiched between aluminum sheets. The formulation was cured in two stages: first stage involves curing at $120^{\circ} \mathrm{C}$ for 1 hour, and then followed by curing at $150{ }^{\circ} \mathrm{C}$ for 3 hours.

Table 1. Polymer Composition

\begin{tabular}{|c|c|c|c|}
\hline Sample \# & AE Molar Ratio & AE Weight Ratio & Catalyst (\% wt. total) \\
\hline S1 & 0.5 & 0.32 & 2 \\
\hline S2 & 0.5 & 0.32 & 5 \\
\hline S3 & 0.5 & 0.32 & 8 \\
\hline S4 & 0.75 & 0.48 & 5 \\
\hline S5 & 0.75 & 0.48 & 8 \\
\hline S6 & 0.75 & 0.48 & 2 \\
\hline S7 & 1.0 & 0.65 & 5 \\
\hline S8 & 1.0 & 0.65 & 8 \\
\hline S9 & 1.0 & 0.65 & \\
\hline
\end{tabular}

\subsection{Fourier-Transform infrared spectroscopy}


FTIR analysis was performed using a Thermo Scientific Nicolet 8700 FTIR spectrometer using a potassium bromide crystal. The cured thermosets were characterized by Attenuated Total Reflectance-FTIR (ATR-FTIR) spectroscopy using a Bruker Vertex 70 HTS-XT equipped with Pike MiRacle (zinc selenide crystal plates). This crystal has a penetration depth of $2.00 \mu \mathrm{m}$ at $45^{\circ}$. For both transmission and reflectance FTIR, the spectra acquisition was based on 32 scans with data spacing of $4.0 \mathrm{~cm}^{-1}$.

\subsection{Soxhlet extraction}

Solvent extraction of the epoxy-anhydride thermosets was carried out using acetone $(\mathrm{BP}=56$ ${ }^{\circ} \mathrm{C}$ ). Soxhlet extraction was conducted for partially and fully cured thermoset samples. For partially cured samples (cured at $120^{\circ} \mathrm{C}$ for 1 hour), the samples were extracted for 6 hours. For fully cured samples, the samples were extracted for 17 hours. The gel content of the thermoset samples was calculated by the weight percentage of the remaining material compared to the total initial weight. Furthermore, chemical analysis of the sol content was conducted by transmission FTIR spectroscopy.

\subsection{Moisture Uptake}

Water absorption measurements were conducted through a gravimetric process. The shape of the thermoset sample was a circular disk with $40 \mathrm{~mm}$ diameter $\times 2 \mathrm{~mm}$ thickness. The specimens were fully immersed in deionized water at room temperature $\left(19^{\circ} \mathrm{C}\right)$. The weight of the specimens was measured after 1 week and 1 month of immersion.

\subsection{Dynamic mechanical analysis}

Thermo-mechanical properties of the thermosets were characterized using dynamic mechanical analysis (DMA) equipped with a 3-point bending clamp. The instrument used is a Q800 DMA from TA Instruments. The sample size was $50 \mathrm{~mm} \times 10 \mathrm{~mm} \times 3 \mathrm{~mm}$. The sample was heated from $-100{ }^{\circ} \mathrm{C}-200{ }^{\circ} \mathrm{C}$ at a heating rate of $5{ }^{\circ} \mathrm{C} / \mathrm{min}$ and a frequency of $1 \mathrm{~Hz}$. The glass transition temperature $\left(T_{g}\right)$ was determined as the temperature of the $\tan \delta$ maximum.

\subsection{Tensile testing}

Tensile testing of the bio-based thermosets was conducted using an Instron 5567 load frame with a $2 \mathrm{kN}$ load cell at a rate of $5 \mathrm{~mm} / \mathrm{min}$. The specimen shape is a dogbone style Type 1 based on ASTM D638, with thickness of $3.4 \mathrm{~mm}$ and width of $10 \mathrm{~mm}$. The grip separation distance of the tensile testing was $115 \mathrm{~mm}$, and the effective gauge length was $50 \mathrm{~mm}$. The tensile 
properties of each sample are reported as the average of five measurements of different specimens.

\section{Results and Discussion}

\subsection{Epoxy-anhydride curing reaction}

Epoxy-anhydride polymerization can undergo both a catalyzed and non-catalyzed reaction. The uncatalyzed reaction of ESS and MHHPA may be possible through the presence of hydroxyl groups in the sucrose ester (the sucrose is not fully esterified) and/or acid impurities in the anhydride crosslinker. However, a previous study on the curing kinetics of the ESS/MHHPA reaction reveals that this uncatalyzed reaction is minimal, and the curing process is dominated by a catalyzed reaction mechanism [39].

Figure 2 shows the FTIR spectra of the raw materials and a cured thermoset sample. The formation of polyester linkages is confirmed by the presence of carbonyl peaks at $1732 \mathrm{~cm}^{-1}$. These carbonyl ester linkages slightly overlap with the carbonyl ester peak of ESS at $1743 \mathrm{~cm}^{-1}$. Furthermore, the presence of anhydride carbonyl peaks at 1857 and $1780 \mathrm{~cm}^{-1}$ are no longer detected in the cured material. Unfortunately, it is challenging to confirm and quantify the amount of polyether linkages in the thermoset system through FTIR analysis, since the C-O ether peak may overlap with $\mathrm{C}-\mathrm{O}$ of esters and carboxylic acids. 


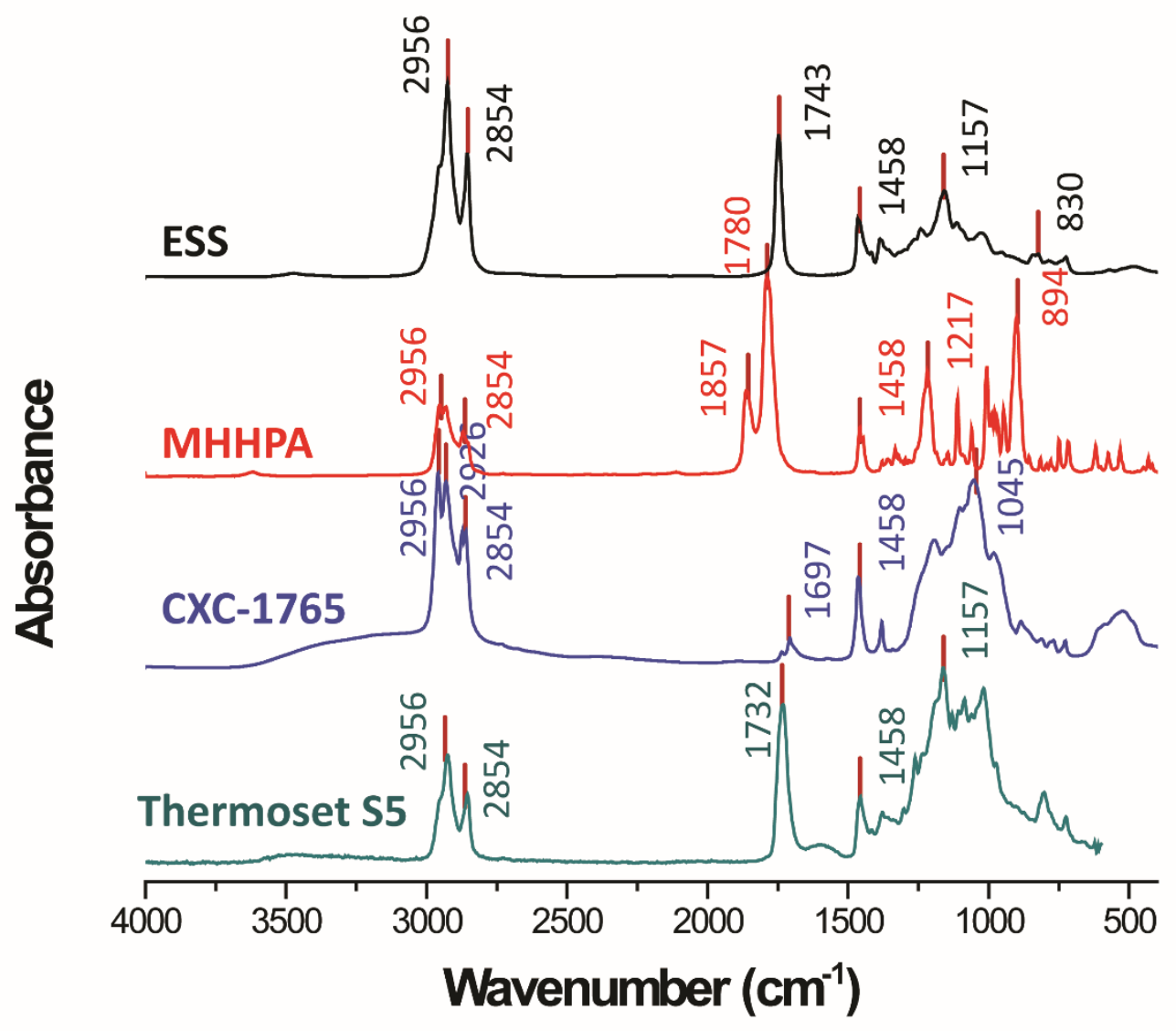

Figure 2. FTIR spectra of the raw materials and cured thermoset S5.

To form the thermosets, the first curing step is done in an open-face molding plate. Therefore, some of the anhydride and catalyst may evaporate due to their volatility at the curing temperature. Even after the second curing step in the closed mold system, further loss of material can occur. The amount of evaporation during the curing process is shown in Table 2; the listed value is the average and standard deviation of 3 samples. Overall, most of the samples retained $90 \%+$ of their initial weight after the full curing process. The highest weight loss was observed for Sample 7, and the lowest was observed for Sample 8. This observation was not unexpected for two reasons: the viscosity of the formulation and the expected rate of polymerization. A high AE equivalent ratio means a high amount of anhydride in the formulation, thus leading to low viscosity and ability of the anhydride to diffuse through the system. Then, it is expected that with a high catalyst content, the polymerization reaction occurs faster, thus the components are able to be incorporated into the network faster and the amount of 
evaporation is limited. A previous study using thermogravimetric analysis of the raw materials indicated that MHHPA crosslinker and CXC 1765 catalyst started to significantly lose its weight at $110{ }^{\circ} \mathrm{C}$, while ESS started to decompose at $332{ }^{\circ} \mathrm{C}$ [39]. Therefore, the weight loss observed in this experiment is likely to be due to the evaporation of MHHPA crosslinker and dissociation of carboxyl diluents from the CXC 1765 catalyst.

Table 2. Weight retained during curing, gel fraction, and moisture uptake of the thermoset samples

\begin{tabular}{|c|c|c|c|c|c|c|}
\hline \multirow{2}{*}{ Sample \# } & \multicolumn{2}{|c|}{$\begin{array}{c}\text { Weight Retained } \\
\text { During Curing (\%) }\end{array}$} & \multicolumn{2}{c|}{ Gel Fraction (\%) } & \multicolumn{2}{c|}{ Moisture Uptake (\%) } \\
\cline { 2 - 7 } & $\begin{array}{c}\text { Partially- } \\
\text { cured* }\end{array}$ & $\begin{array}{c}\text { Fully- } \\
\text { cured** }\end{array}$ & $\begin{array}{c}\text { Partially- } \\
\text { cured* }\end{array}$ & $\begin{array}{c}\text { Fully- } \\
\text { cured** }\end{array}$ & 1 week & 1 month \\
\hline S1 & $93.4 \pm 0.6$ & $92.5 \pm 0.2$ & $66.2 \pm 0.6$ & $98.3 \pm 0.1$ & $0.59 \pm 0.03$ & $0.69 \pm 0.04$ \\
\hline S2 & $93.3 \pm 0.5$ & $93.3 \pm 0.3$ & $71.2 \pm 3.4$ & $98.1 \pm 0.3$ & $0.61 \pm 0.03$ & $0.86 \pm 0.13$ \\
\hline S3 & $94.5 \pm 0.2$ & $95.8 \pm 0.1$ & $89.1 \pm 1.9$ & $97.5 \pm 0.4$ & $0.64 \pm 0.02$ & $1.10 \pm 0.07$ \\
\hline S4 & $89.1 \pm 0.2$ & $85.2 \pm 0.8$ & $68.1 \pm 1.1$ & $98.4 \pm 0.3$ & $0.92 \pm 0.02$ & $1.14 \pm 0.03$ \\
\hline S5 & $91.5 \pm 0.3$ & $91.4 \pm 0.1$ & $80.2 \pm 0.9$ & $98.7 \pm 0.3$ & $0.89 \pm 0.06$ & $1.15 \pm 0.07$ \\
\hline S6 & $93.3 \pm 0.3$ & $91.7 \pm 0.9$ & $87.1 \pm 0.3$ & $97.1 \pm 0.6$ & $0.84 \pm 0.04$ & $1.53 \pm 0.20$ \\
\hline S7 & $86.5 \pm 0.3$ & $81.8 \pm 1.2$ & $58.9 \pm 1.8$ & $95.6 \pm 0.5$ & $1.08 \pm 0.04$ & $1.50 \pm 0.12$ \\
\hline S8 & $89.0 \pm 0.2$ & $88.5 \pm 0.3$ & $74.0 \pm 1.7$ & $94.6 \pm 0.4$ & $1.11 \pm 0.05$ & $1.81 \pm 0.02$ \\
\hline S9 & $91.5 \pm 0.6$ & $90.6 \pm 0.2$ & $79.5 \pm 0.8$ & $95.0 \pm 1.5$ & $1.09 \pm 0.02$ & $1.62 \pm 0.03$ \\
\hline
\end{tabular}

*Partially-cured samples: Samples that has been cured at $120^{\circ} \mathrm{C}$ for 1 hour

**Fully-cured samples: Samples that has been cured at $120{ }^{\circ} \mathrm{C}$ for 1 hour $+150{ }^{\circ} \mathrm{C}$ for 3 hours

\subsection{Gel content}

Soxhlet extraction was conducted to determine the gel content of the epoxy-anhydride thermosets, which may be related to the extent of cure. Table 2 list the gel content of the samples, after the partial and full curing process. As expected, the gel content after partial curing is significantly lower than the after the complete curing process. The gel contents of the partially-cured samples are fairly low; samples containing $2 \%$ wt. catalyst loading only retain $60 \%$ of its weight after Soxhlet extraction. In contrast, the gel content of all fully-cured samples are more than $94 \%$, which indicates a high degree of conversion of the components. It is very 
surprising that the gel content of partially-cured and fully-cured samples can differ up to 37\%, e.g. Sample 7; this observation indicates that significant additional curing occurs during the second stage of the curing process. It can be clearly seen that the amount of gel in the partially cured samples are affected by the catalyst amount; as the catalyst amount was increased, the gel content significantly increased. The effect of AE molar ratio on the gel content of the fully cured resins is more ambiguous, and there might be a cross interaction between the $\mathrm{AE}$ molar ratio and the catalyst amount. This situation can be seen by comparing the increase in the gel content at a certain AE molar ratio as the catalyst amount was increased. For example, when comparing Samples 1 and 2 (samples with AE molar ratio $=0.5$ ), as the catalyst amount was increased from 2 to 5 wt. \%, the gel content only differs by 5\%. In contrast, when comparing Samples 7 and 8 (samples with AE molar ratio $=1.0$ ), increasing the catalyst amount from 2 to 5 wt. $\%$ results in $15 \%$ difference in the gel content. Unlike the pattern seen in the partially-cured samples, the gel content in the fully-cured samples is more influenced by the AE molar ratio; where the lowest gel content was observed for samples with AE molar ratio $=1.0$.

Figure 3 shows the FTIR spectra of the sol content of the partially-cured samples. For all samples, the spectra indicated that the sol contains the raw materials. Looking at the carbonyl region, the anhydride peaks and the ester peaks from ESS $\left(1740 \mathrm{~cm}^{-1}\right)$ are still observed. As mentioned in the previous section, the reaction between epoxy and anhydride results in ester linkages and carboxylate end-groups. The FTIR peak corresponding to the newly formed ester peak may overlap with the one for the ESS ester peak at $1740 \mathrm{~cm}^{-1}$. Carboxylic acid end-groups can be observed at $1709 \mathrm{~cm}^{-1}$. For samples with an AE molar ratio $=0.5$, the intensity of the hydroxyl region was not as strong. 


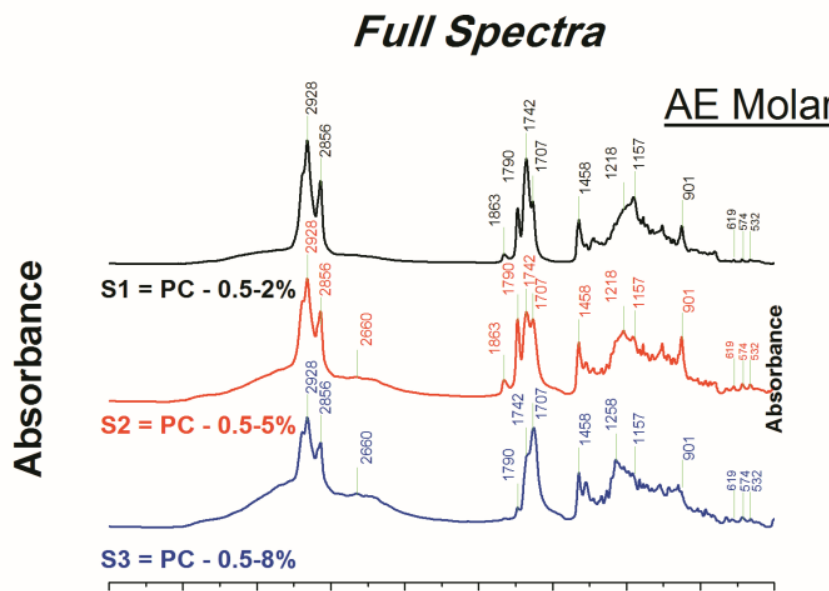

Carbonyl Region
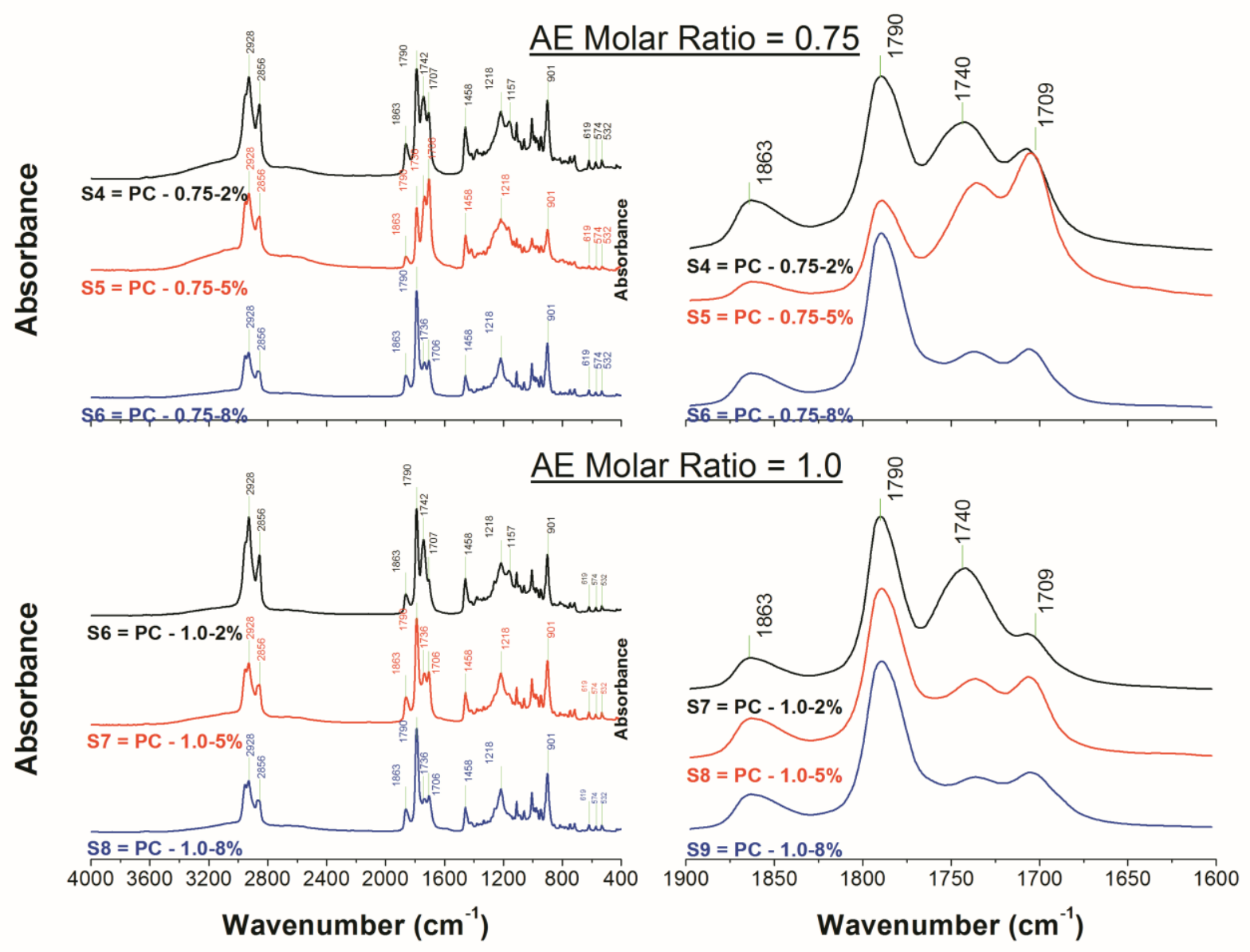

Figure 3. FTIR spectra of sol fraction for partially-cured system 
Figure 4 shows the FTIR spectra for the sol content of the fully-cured samples. No anhydride was observed in the samples, except for Samples 7 and 8. However, for Samples 7 and 8 , only shows trace amounts of anhydride are observed. Looking closely at the carbonyl peak region, the relative peak intensity between the ester $\left(1740 \mathrm{~cm}^{-1}\right)$ and carboxylate $\left(1709 \mathrm{~cm}^{-}\right)$are different for each sample. Samples with an AE molar ratio $=0.5$ are dominated by the ester group. In contrast, samples with $\mathrm{AE}$ molar ratio $=0.75$ and 1.0 , are more dominated by pendant carboxylic acids indicated by the presence of an broad $\mathrm{OH}$ peak in the $2500-3000 \mathrm{~cm}^{-1}$ region.

The amount of sol in the partially-cured samples is predicted to correlate with the amount of initiated polymer chains. The FTIR spectra of the sol fraction show the presence of raw materials, in addition to newly formed functional groups. On the other hand, the amount of sol content in the fully-cured samples is predicted to correlate with the overall network of the final thermoset system. Samples with AE molar ratio 1.0 had the highest sol (lowest gel) content among all samples, and the FTIR spectra of the sol content indicates the presence of carboxylic acid/carboxylate pendant group. This observation suggests that there may be excess anhydride in the reaction through the carboxylate pendant group that cannot react with epoxy functionalities since the system has already vitrified. 


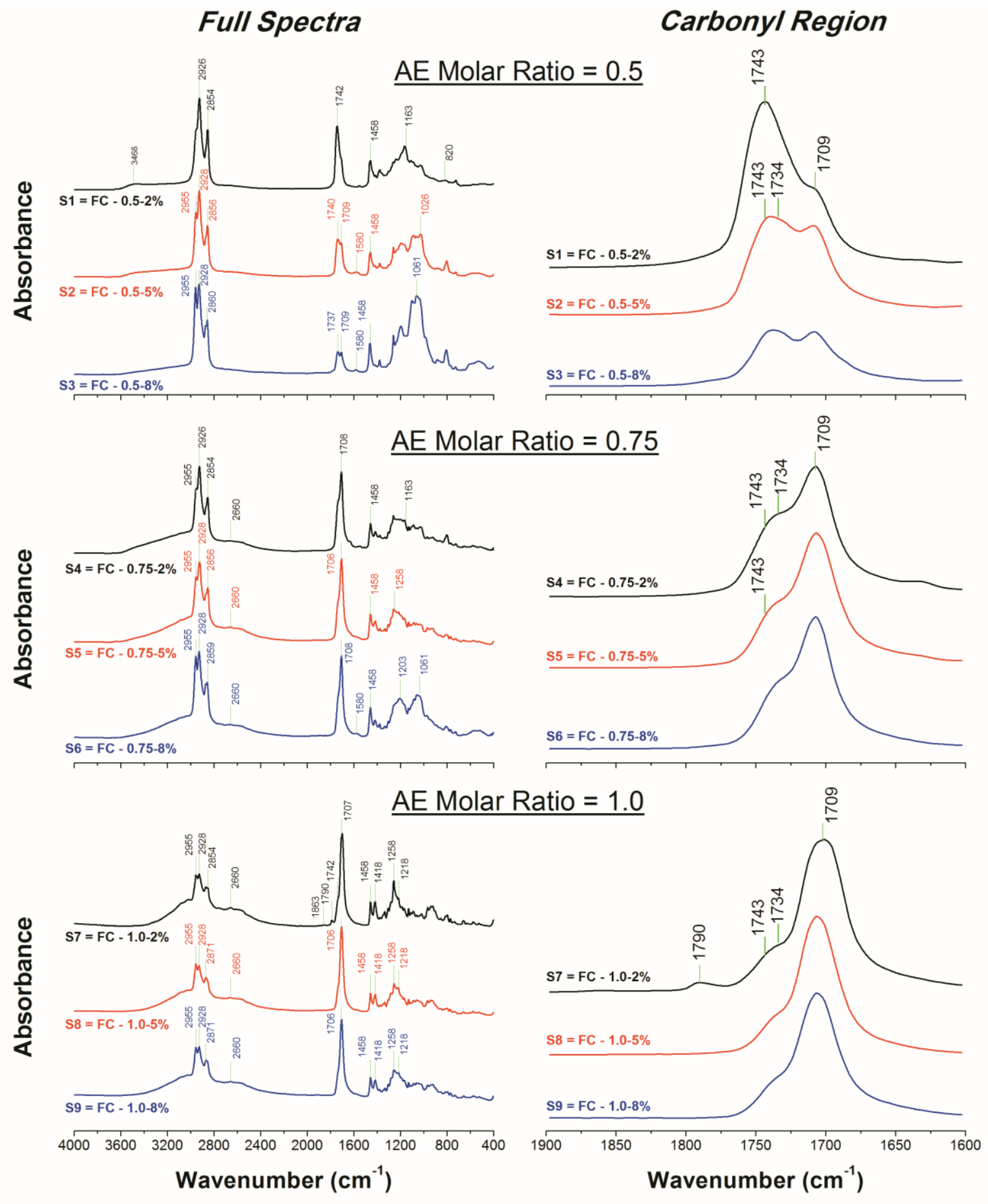

Figure 4. FTIR spectra of sol fraction of fully-cured samples 


\subsection{Moisture Uptake}

Determination of the amount of water absorption of the thermoset systems can indicate the hydrostability of the systems. Table 2 shows the weight gain after 1 week and 1 month of water immersion, and Figure 12 shows the appearance of the thermosets 1 month of immersion. As shown in Table 2, all of the samples have fairly low water absorption, less than $2 \%$. Compared to a similar bio-based thermoset system based on epoxidized vegetable oil, most of the samples in this study show lower water absorption [40,41]. The highest absorption is observed for the samples with AE molar ratio = 1.0. This observation is expected due to the presence of carboxylic acid and/or hydroxyl end groups in those thermosets; these functional groups are hydrophilic, thus able to attract and retain water. In contrast to the water absorption, the appearance of the thermoset samples appears to be related to the amount of catalyst used in the system. As can be seen in Figure 9, there are white blemishes observed on the surfaces of the samples. The amount of the blemishes increases with increasing catalyst amount and decreasing AE molar ratio. These white blemishes are attributed to the precipitation of the catalyst in the presence of water.

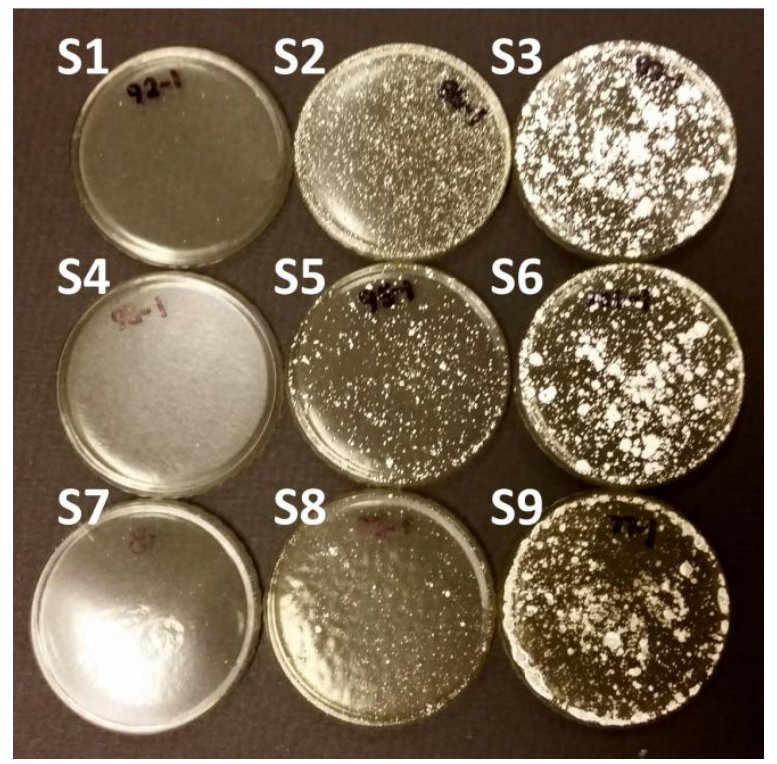

Figure 5. The appearance of the samples after 1 month water immersion

\subsection{Viscoelastic properties}

The goal of the study is to understand the molecular network structure by analyzing the dynamic mechanical properties of the thermosets, which includes the glass transition 
temperature, crosslink density, and the temperature dependence of the storage modulus, loss modulus, and tan delta. Figures 6-8 show the temperature dependence of the storage modulus, loss modulus, and tan delta of the thermosets. The glass transition temperature can be determined through 3 different methods: the onset of the storage modulus drop $\left(T_{g, S M}\right)$, the peak maximum of the loss modulus $\left(T_{g, L M}\right)$, and the peak maximum of the tan delta $\left(T_{g, T D}\right)$. Table 3 lists the $T_{g}$ values of the thermosets derived from these three methods.

The storage modulus in the viscoelastic polymer represents the elastic portion, or solid-like behavior of the material. In Figure 6, the storage modulus can be divided to be 3 regions: glassy state, glass transition region, and rubbery state. In the glassy state, as the samples are heated, the storage modulus value is decreasing, indicating more movement in the polymer network. Looking at the shape of the curves, samples with lower AE molar ratio tend to experience a higher decrease rate of the storage modulus values. Then, samples with higher catalyst amount tend to have longer temperature range for its glassy state. The temperature at the onset of the rapid decrease in the storage modulus can be used to determine the glass transition temperature, $T_{g}$, of the materials $\left(T_{g}, S M\right)$. Using this analysis, formulations with lower AE molar ratio and catalyst amount produce thermoset samples with lower $T_{g, S M}$. Based on the storage modulus of the thermosets in the glass transition state, the thermoset samples may undergo different stages of relaxation. For some samples, the storage modulus as a function of temperature does not undergo a constant decreasing rate. Sample 5 showed this occurrence more clearly than the other samples. The storage modulus in the rubbery region is used to analyze the crosslink density of the thermoset; this topic will be discussed in a later section. 


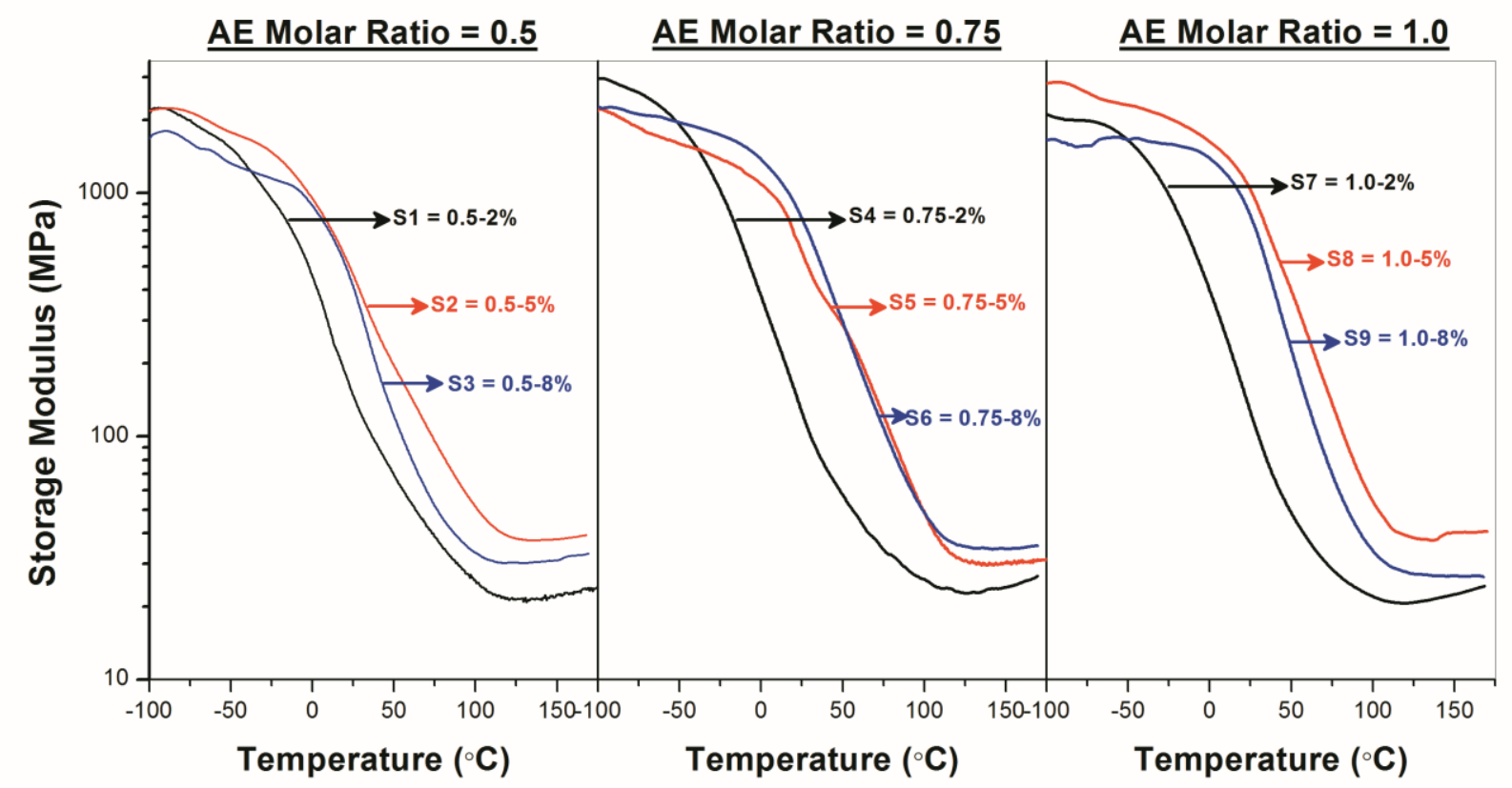

Figure 6. Storage modulus as function of temperatures of the thermoset samples

The loss modulus in the viscoelastic polymer represents the viscous portion, or liquid-like behavior of the thermosets. Figure 7 shows the loss modulus curve as a function of temperature. For the thermosets with $2 \%$ wt. catalyst, the loss modulus starts to increase significantly as soon as the samples were heated. In contrast, the loss modulus did not increase immediately for other samples. This observation has a similar pattern to what has been observed with the storage modulus, i.e. storage/loss modulus changes significantly for samples with $2 \%$ wt. catalyst. Furthermore, the width of the loss modulus curves for thermosets with 2 and 5\% wt. catalyst is shown to be broader than the samples with $8 \%$ wt. catalyst amount. The peak maximum of the loss modulus curve can be used as another indication for the $T_{g}$ of the polymer $\left(T_{g}, L M\right)$. Again, thermosets with $2 \%$ wt. catalyst showed significantly lower $T_{g}$ values compared to other samples. However, the effect of AE molar ratio is only observed with thermosets having $8 \%$ wt. catalyst amount. 


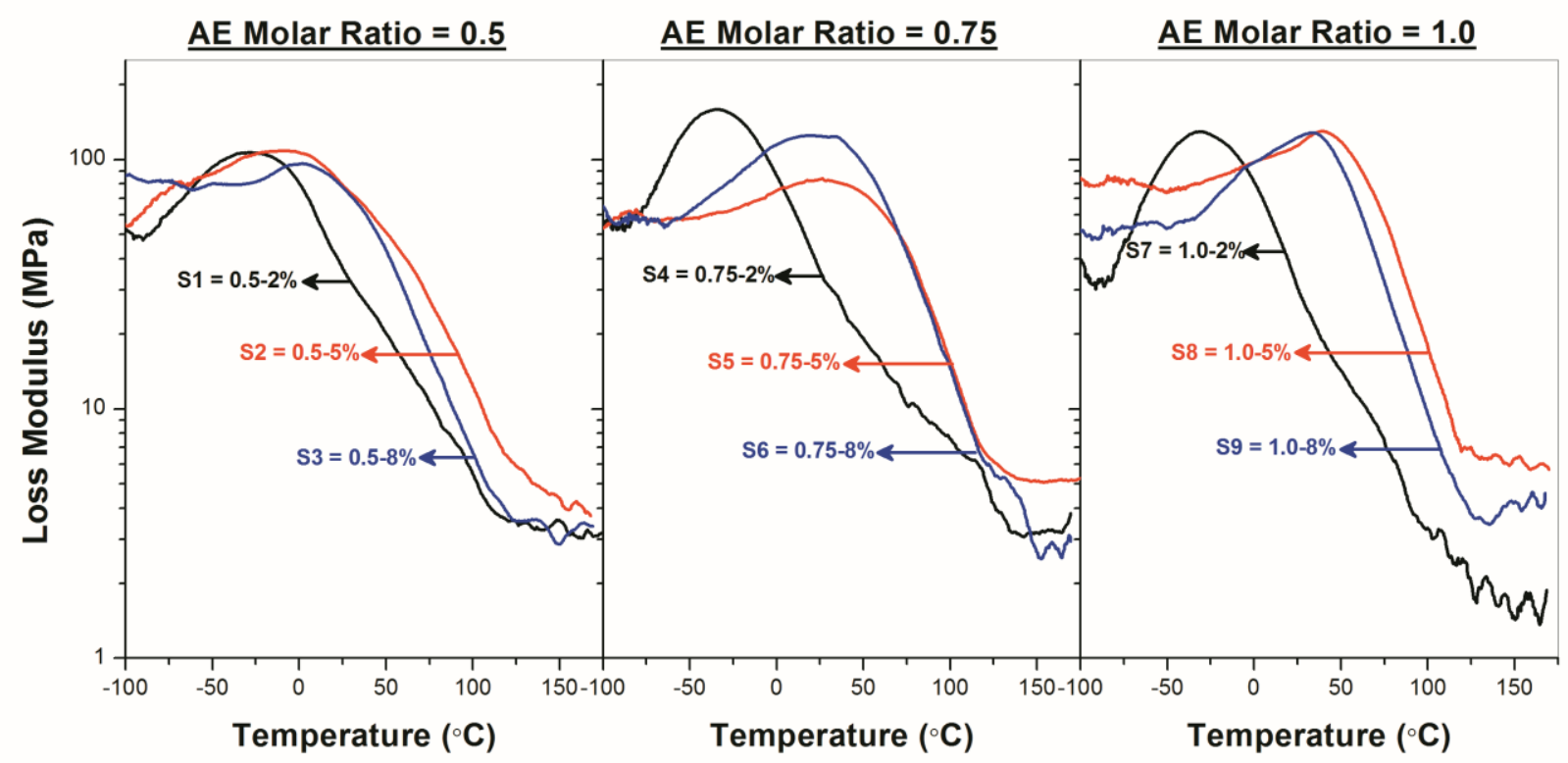

Figure 7. Loss modulus as function of temperatures of the thermoset samples

The ratio of loss modulus over the storage modulus is the tan delta. The peak maximum of the tan delta is commonly identified as the $T_{g}$ of a polymer $\left(T_{g}, T D\right)$. The tan delta curve of the thermoset samples is shown in Figure 8. The highest $T_{g, T D}$ was observed for $\mathrm{S} 5$ and $\mathrm{S} 8$, that is $79.1^{\circ} \mathrm{C}$ and $78.8^{\circ} \mathrm{C}$, respectively. Furthermore, the width of the curve or the breadth of the tan delta peak may suggest the degree of homogeneity of the network. For all samples, the width of the peak is fairly broad, up to $100{ }^{\circ} \mathrm{C}$; this observation is similar what has been seen with vegetable oil-based thermosets [37]. Narrow peak width and high peak intensity was observed for higher AE molar ratio and catalyst amount. Interestingly, samples with $2 \%$ catalyst (S1, S4, and S7) tend to have fairly broad tan delta peaks. Furthermore, the presence of multiple tan delta maxima may be observed for S4. This observation may indicate that samples made using low catalyst level have more heterogeneity in the polymer network structure. 


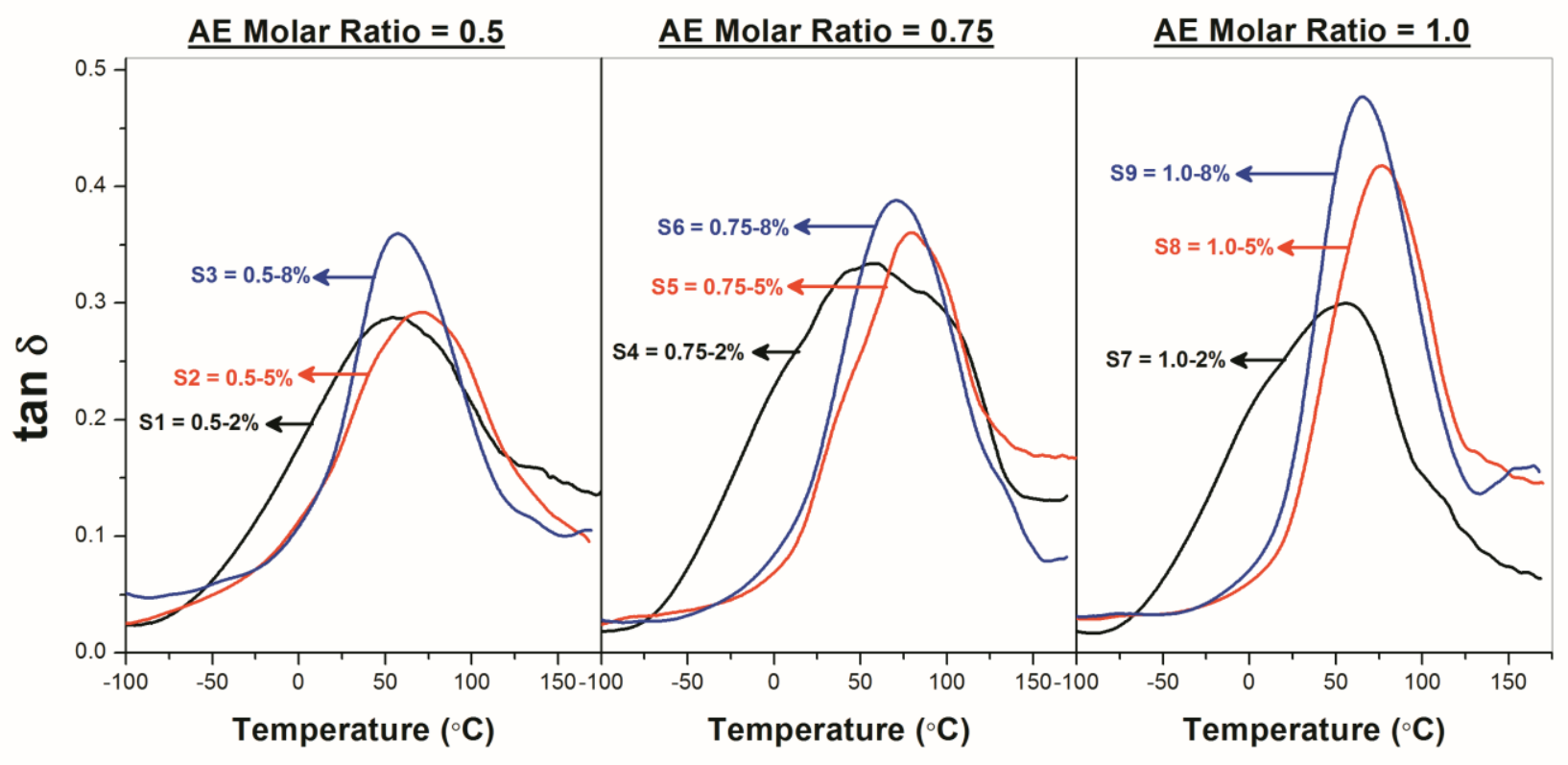

Figure 8. tan delta as function of temperatures of the thermoset samples

The molecular network structure of ESS-MHHPA can be characterized by the crosslink density and the molecular weight between crosslinks. This information can be calculated from the storage modulus in the rubbery region through rubber elasticity theory:

$$
E^{\prime}=3 v_{e} R T
$$

\section{Equation 1}

where $E^{\prime}$ is the storage modulus, $v_{e}$ is the crosslink density, $R$ is the gas constant, and $T$ is the temperature [42]. For this equation to be valid, the temperature chosen should be well above the $T_{g}$ of the thermosets. Often times, the crosslink density is calculated from the storage modulus at $T_{g, T D}+60^{\circ} \mathrm{C}$. However, due to the width of the tan delta curves in this experiment, the chosen temperature is $150{ }^{\circ} \mathrm{C}$, temperature above $T_{g, T D}+60{ }^{\circ} \mathrm{C}$ where the storage modulus is in the plateau region. Table 3 shows the crosslink density values of the bio-based epoxy-anhydride thermosets.

Often, high crosslink density is believed to result in higher $T_{g}$ values and vice versa, such as displayed for Sample 5 with the highest $T_{g}$ and crosslink density. However, this assumption did not entirely hold true in this study. For example, Sample 7 shows lower $T_{g}$ value compared to Sample 9; yet Sample 7 has comparatively lower crosslink density than Sample 9. This observation suggests that the mechanical properties of the thermosets not only depends on the crosslink density of the network, but also on the composition of the polymer backbone. 
Table 3. DMA analysis of thermoset samples

\begin{tabular}{|c|c|c|c|c|c|c|}
\hline \multirow{2}{*}{ Sample \# } & \multicolumn{3}{|c|}{ Glass Transition Temperature $\left({ }^{\circ} \mathbf{C}\right)$} & \multicolumn{2}{|c|}{$\mathbf{E}^{\prime}(\mathbf{M P a})$} & \multirow{2}{*}{$\begin{array}{c}v_{e} \\
\left(\mathrm{~mm}^{3} / \mathrm{mol}\right)\end{array}$} \\
\hline & $T T_{g, S M}$ & $\overline{T_{g, L M}}$ & $T T_{g, T D}$ & At $25^{\circ} \mathrm{C}$ & At $150{ }^{\circ} \mathrm{C}$ & \\
\hline S1 & -56.9 & -36.7 & 59.0 & 118 & 21.7 & 2.06 \\
\hline S2 & -53.6 & -34.2 & 57.0 & 126 & 23.9 & 2.27 \\
\hline S3 & -42.7 & -30.4 & 52.2 & 119 & 22.3 & 2.11 \\
\hline S4 & -18.3 & -3.7 & 68.5 & 423 & 37.8 & 3.59 \\
\hline S5 & 6.7 & 5.6 & 79.1 & 807 & 44.1 & 4.18 \\
\hline S6 & 13.9 & 21.0 & 69.2 & 788 & 34.5 & 3.27 \\
\hline S7 & 3.3 & 1.3 & 57.7 & 413 & 30.8 & 2.92 \\
\hline S8 & 18.1 & 41.4 & 78.8 & 1029 & 40.3 & 3.82 \\
\hline S9 & 12.2 & 24.6 & 61.3 & 712 & 25.6 & 2.42 \\
\hline
\end{tabular}

\subsection{Tensile testing}

Tensile testing was conducted to determine the Young's modulus, tensile strength, elongation at break, and tensile toughness of the thermoset samples. Figure 9 shows representative stressstrain curves, and Table 4 provides the analysis values. Tensile toughness values were calculated from the area under stress-strain curve. The tensile properties of samples with $0.5 \mathrm{AE}$ molar ratio and 2\% catalyst amount (S1-S4 and S7) are significantly different than samples with higher AE molar ratio and catalyst amount. Looking at their stress-strain curves, S1-S3 and S7 behave more like rubbery materials, while the others tend to be more brittle. This observation is further confirmed by looking at the Young's modulus values. For the rubbery-like materials (S1-S3, S7), the Young's modulus values are fairly low, $\leq 300 \mathrm{MPa}$. In contrast, for brittle-like materials (S5, S6, S8, and S9), the Young's modulus values are close to $1 \mathrm{GPa}$. The tensile stress-strain curve for S4 is quite interesting; they have rubbery-like Young's modulus values at $260 \mathrm{MPa}$, yet brittle-like percent of elongation at $4.2 \%$. Surprisingly, regardless of the shape of the stressstrain curve (rubbery vs. brittle), the toughness of most of the thermoset samples is fairly similar with values in the range of $800-1400 \mathrm{~kJ} / \mathrm{m}^{3}$. 


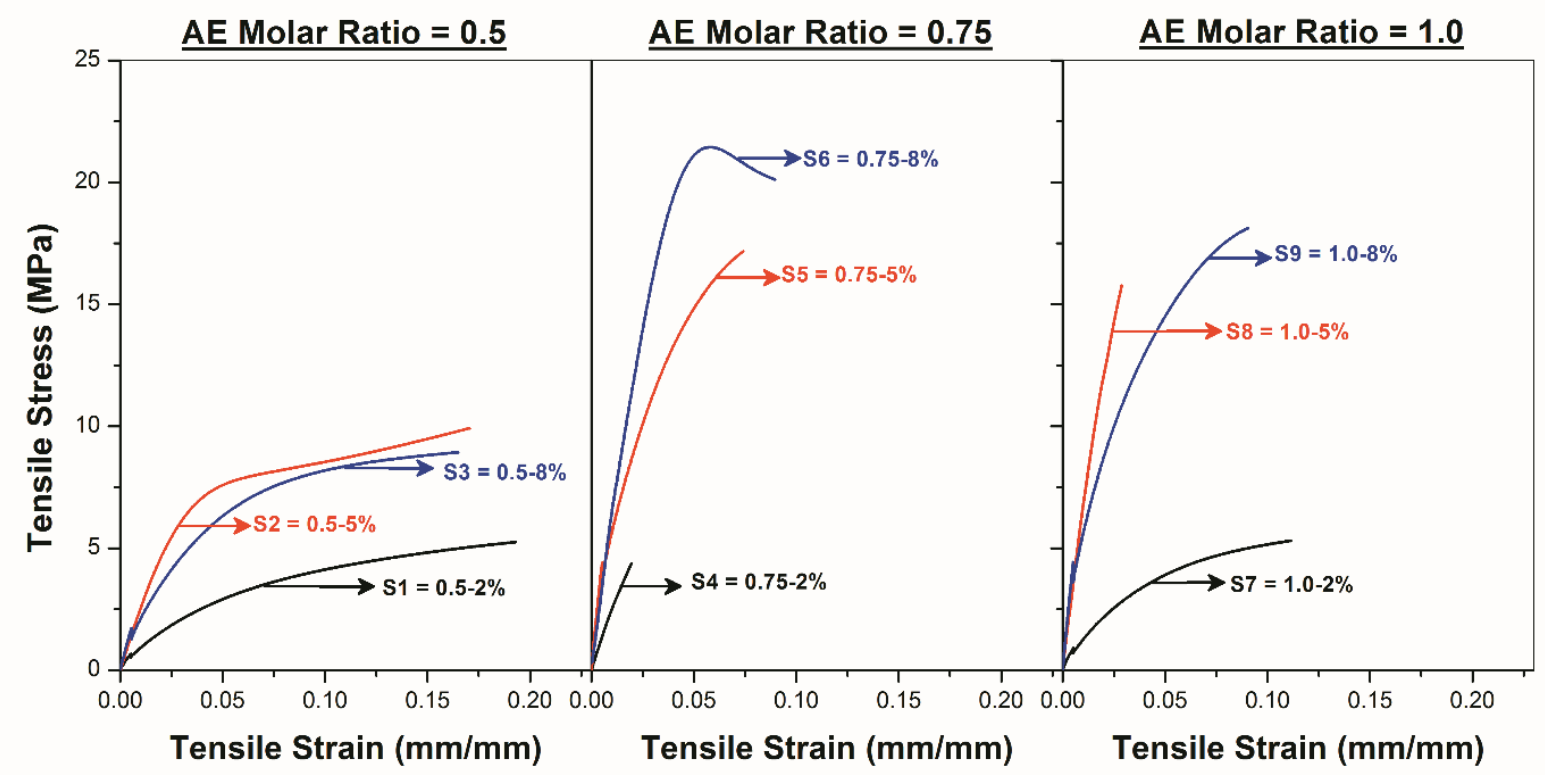

Figure 9. Representative stress-strain curves for the thermoset samples

Table 4. Tensile properties of the thermoset samples

\begin{tabular}{|c|c|c|c|c|}
\hline Sample \# & $\begin{array}{c}\text { Young's } \\
\text { Modulus (MPa) }\end{array}$ & $\begin{array}{c}\text { Tensile Strength } \\
\text { (MPa) }\end{array}$ & $\begin{array}{c}\text { Elongation at } \\
\text { Break } \\
(\boldsymbol{\%})\end{array}$ & $\begin{array}{c}\text { Tensile } \\
\text { Toughness } \\
\left(\mathbf{k J} / \mathbf{m}^{\mathbf{3}}\right)\end{array}$ \\
\hline S1 & $166 \pm 43$ & $5.9 \pm 0.9$ & $15.9 \pm 1.4$ & $731 \pm 51$ \\
\hline S2 & $283 \pm 16$ & $10.1 \pm 0.3$ & $19.5 \pm 3.5$ & $1320 \pm 254$ \\
\hline S3 & $333 \pm 10$ & $9.0 \pm 0.3$ & $14.9 \pm 3.0$ & $1193 \pm 339$ \\
\hline S4 & $263 \pm 8$ & $4.2 \pm 0.3$ & $2.3 \pm 0.2$ & $45 \pm 8$ \\
\hline S5 & $866 \pm 39$ & $17.5 \pm 2.3$ & $6.9 \pm 3.1$ & $1141 \pm 535$ \\
\hline S6 & $710 \pm 43$ & $21.6 \pm 0.3$ & $7.5 \pm 0.9$ & $1339 \pm 320$ \\
\hline S7 & $290 \pm 108$ & $6.9 \pm 1.9$ & $7.6 \pm 2.5$ & $377 \pm 133$ \\
\hline S8 & $717 \pm 38$ & $15.6 \pm 0.4$ & $2.9 \pm 0.2$ & $251 \pm 25$ \\
\hline S9 & $910 \pm 75$ & $17.2 \pm 3.6$ & $5.4 \pm 1.7$ & $789 \pm 436$ \\
\hline
\end{tabular}

\subsection{Structure-property relationships of ESS-MHHPA thermosets}

Generally speaking, higher $T_{g}$ and Young's modulus values are often caused by more highly crosslinked materials. However, this premise did not entirely hold true in this study. For example, S1 and S9 have fairly similar $T_{g, T D}$ and crosslink density values, yet their $T_{g, S M}$ and $T_{g}$, 
$L M$ values are quite different. Furthermore, the tensile properties also show a different failure behavior: $\mathrm{S} 1$ behaves more like a rubbery material, while $\mathrm{S} 9$ is more like a ductile material. It is widely known that the molecular network structures of epoxy-anhydride thermosets are fairly complex due to many possible reactions that can occur at the same time. In this study, the complexity is further enhanced when ESS was used, since ESS has a broad range of functionalities [14]. Based on information above regarding the $T_{g}$, crosslink density and tensile properties, the molecular network of ESS-MHHPA is shown to be influenced by both the AE molar ratio and the catalyst amount; there may also be a synergistic effect between the AE molar ratio and the catalyst amount. The complexity of the molecular network may be due to the following factors: intermolecular vs. intramolecular linkages between ESS molecules, polyesterification vs. polyetherification, entanglements vs. actual crosslink of the ESS-MHHPA network, and dangling ends from unreacted functional groups. First, as the network is being formed, a carboxylic acid group can react with an epoxy group either on the same molecule or a different ESS molecule, leading to either an intra-molecular linkage or an inter-molecular linkage [43]. A higher fraction of intermolecular structures may result in a better network structure and higher modulus values. Second, due to the high number of epoxy functional groups and the complicated structure of ESS, the fatty acid chains between the same or different ESS molecules might entangle with each other [44]. When the epoxy groups subsequently react, a trapped entanglement network may form. This trapped entanglement can also act as a crosslink, and thus provide higher modulus. Furthermore, note that $v_{e}$ determined using Equation1 does not separate trapped entanglements from actual crosslinks. Third, the epoxy-anhydride curing process may result in both polyesterification and polyetherification reactions; polyesterification occurs when epoxy groups react with anhydride, while polyetherification is produced when epoxy groups react with a hydroxyl group formed from another epoxy. It is expected that these two linkages have different bond strengths, and thus might result in different thermoset modulus. Finally, lower modulus and $T_{g}$ of the thermoset may also be caused by the amount of dangling ends from unreacted functional groups.

\section{Conclusion}

A series of novel bio-based thermosets were successfully prepared by reacting epoxidized sucrose soyate with cycloaliphatic anhydride crosslinker. It was found that the change in the 
compositional variables, such as anhydride-to-epoxy (AE) molar ratio and catalyst amount, results in unique chemical network and thus mechanical properties which include $T_{g}$, crosslink density, tensile properties, and moisture uptake. In other words, it is suggested that the mechanical properties of the thermoset depends not only on the crosslink density of the network, but also on the polymer backbone. This unique chemical network was predicted to be attributed from the following factors: intermolecular vs. intramolecular linkages between ESS molecules, polyesterification vs. polyetherification, entanglements vs. actual crosslink of the ESS-MHHPA network, and dangling ends from unreacted functional groups. High $T_{g}$ and Young's modulus values can be obtained with formulation containing less than equimolar ratio of anhydride-toepoxy and higher catalyst amount. Yet, the tunability in the mechanical properties of these thermosets samples by changing its compositional variation is beneficial in producing composite materials for different applications with a broad range of properties.

\section{Acknowledgements:}

The authors are very grateful for the funding provided by National Science Foundation Structural Materials and Mechanics program under grant number CMMI-1130590. 


\section{References}

[1] Z. Liu, G. Kraus, Green Materials from Plant Oils, RSC Green Chemistry ed., Royal Society of Chemistry, Cambridge, UK, 2014.

[2] Y. Xia, R.C. Larock, Vegetable oil-based polymeric materials: synthesis, properties, and applications, Green Chemistry, 12 (2010) 1893-1909.

[3] S. Miao, P. Wang, Z. Su, S. Zhang, Vegetable-oil-based polymers as future polymeric biomaterials, Acta Biomaterialia, 10 (2014) 1692-1704.

[4] R. Auvergne, S. Caillol, G. David, B. Boutevin, J.-P. Pascault, Biobased Thermosetting Epoxy: Present and Future, Chemical Reviews, 114 (2013) 1082-1115.

[5] J.M. Raquez, M. Deléglise, M.F. Lacrampe, P. Krawczak, Thermosetting (bio)materials derived from renewable resources: A critical review, Progress in Polymer Science, 35 (2010) 487-509.

[6] L. Montero de Espinosa, M.A.R. Meier, Plant oils: The perfect renewable resource for polymer science?!, European Polymer Journal, 47 (2011) 837-852.

[7] D.P. Pfister, Y. Xia, R.C. Larock, Recent Advances in Vegetable Oil-Based Polyurethanes, ChemSusChem, 4 (2011) 703-717.

[8] M. Desroches, M. Escouvois, R. Auvergne, S. Caillol, B. Boutevin, From Vegetable Oils to Polyurethanes: Synthetic Routes to Polyols and Main Industrial Products, Polymer Reviews, 52 (2012) 38-79.

[9] M.D. Soucek, T. Khattab, J. Wu, Review of autoxidation and driers, Progress in Organic Coatings, 73 (2012) 435-454.

[10] J.L. Scala, R.P. Wool, The effect of fatty acid composition on the acrylation kinetics of epoidized triacyclycerols, Journal of American Oil Chemists' Society, 79 (2002) 59-63.

[11] M. Gonzalez-Lopez, J.T. Shaw, Cyclic anhydrides in formal cycloadditions and multicomponent reactions, Chemical Reviews, 109 (2009) 164-189.

[12] A. Paramarta, X. Pan, D.C. Webster, Highly functional acrylated biobased resin system for uv-curable coatings, Radtech Report, (2013) 26-32.

[13] H. Pelletier, N. Belgacem, A. Gandini, Acrylated vegetable oils as photocrosslinkable materials, Journal of Applied Polymer Science, 99 (2006) 3218-3221. 
[14] T. Nelson, B. Masaki, Z. Morseth, D. Webster, Highly functional biobased polyols and their use in melamine-formaldehyde coatings, J Coat Technol Res, 10 (2013) 757-767.

[15] T.J. Nelson, L. Bultema, N. Eidenschink, D.C. Webster, Bio-Based High Functionality Polyols and Their Use in 1K Polyurethane Coatings, Journal of Renewable Materials, 1 (2013) 141-153.

[16] T.J. Nelson, Novel bio-based resins for high-performance coatings, in, North Dakota State University, Ann Arbor, 2013, pp. 195.

[17] X. Pan, D.C. Webster, New Biobased High Functionality Polyols and Their Use in Polyurethane Coatings, ChemSusChem, 5 (2012) 419-429.

[18] A. Gandini, T.M. Lacerda, A.J.F. Carvalho, A straightforward double coupling of furan moieties onto epoxidized triglycerides: synthesis of monomers based on two renewable resources, Green Chemistry, 15 (2013) 1514-1519.

[19] W. Fisch, W. Hofmann, J. Koskikallio, The curing mechanism of epoxy resins, Journal of Applied Polymer Science, 6 (1956).

[20] E.C. Dearborn, R.M. Fuoss, A.K. MacKenzie, R.G. Shepherd, Epoxy resins from bis-, tris-, and tetrakisglycidyl etheres, Industrial and Engineering Chemistry, 45 (1953) 2715-2721.

[21] L.A. O'Neill, C.P. Cole, Chemical and spectroscopic studies of epoxy resin reactions in the surface coating field, Journal of Applied Chemistry, 6 (1956) 356-364.

[22] R. Wegler, Chemie der polyepoxyde, Angewandte Chemie, 67 (1955) 582-592.

[23] R.F. Fischer, Polyesters from epoxides and anhydrides, Industrial and Engineering Chemistry, 52 (1960) 321-323.

[24] C. Taylor, T. Krosbakken, C.A. Ulven, A. Paramarta, D.C. Webster, Structural quality biocomposites of treated flax fiber with epoxidized sucrose soyate resin, in: International Conference on Composite Materials, Montreal, Canada, 2013.

[25] N. Hosseini, C.A. Ulven, F. Azarmi, D.C. Webster, T.J. Nelson, Utilization of Flax Fibers and Glass Fibers in a Bio-Based Resin, in: ASME 2014 International Mechanical Engineering Congress and Exposition, The American Society of Mechanical Engineers, Montreal, Quebec, Canada, 2014.

[26] J.A. Foulk, M.A. Fuqua, C.A. Ulven, M.M. Alcock, Flax Fibre Quality and Influence on Interfacial Properties of Composites, International Journal of Sustainable Engineering, 3 (2010) 17-24. 
[27] A. O'Donnell, M.A. Dweib, R.P. Wool, Natural fiber composites with plant oil-based resin, Composites Science and Technology, 64 (2004) 1135-1145.

[28] Y. Lu, R.C. Larock, Fabrication, Morphology and Properties of Soybean Oil-Based Composites Reinforced with Continuous Glass Fibers, Macromolecular Materials and Engineering, 292 (2007) 1085-1094.

[29] R.L. Quirino, J. Woodford, R.C. Larock, Soybean and linseed oil-based composites reinforced with wood flour and wood fibers, Journal of Applied Polymer Science, 124 (2012) $1520-1528$.

[30] R. Wang, T. Schuman, CHAPTER 9 Towards Green: A Review of Recent Developments in Bio-renewable Epoxy Resins from Vegetable Oils, in: Green Materials from Plant Oils, The Royal Society of Chemistry, 2015, pp. 202-241.

[31] Z.S. Liu, S.Z. Erhan, P.D. Calvert, Solid freeform fabrication of epoxidized soybean oil/epoxy composite with bis or polyalkyleneamine curing agents, Composites Part A: Applied Science and Manufacturing, 38 (2007) 87-93.

[32] Z.S. Liu, S.Z. Erhan, J. Xu, P.D. Calvert, Development of soybean oil-based composites by solid freeform fabrication method: Epoxidized soybean oil with bis or polyalkyleneamine curing agents system, Journal of Applied Polymer Science, 85 (2002) 2100-2107.

[33] J.V. Crivello, R. Narayan, S.S. Sternstein, Fabrication and mechanical characterization of glass fiber reinforced UV-cured composites from epoxidized vegetable oils, Journal of Applied Polymer Science, 64 (1997) 2073-2087.

[34] S.G. Tan, W.S. Chow, Biobased Epoxidized Vegetable Oils and Its Greener Epoxy Blends: A Review, Polymer-Plastics Technology and Engineering, 49 (2010) 1581-1590.

[35] X. Pan, P. Sengupta, D.C. Webster, Novel biobased epoxy compounds: epoxidized sucrose esters of fatty acids, Green Chemistry, 13 (2011) 965-975.

[36] X. Pan, D.C. Webster, Impact of Structure and Functionality of Core Polyol in Highly Functional Biobased Epoxy Resins, Macromolecular Rapid Communications, 32 (2011) 13241330.

[37] X. Pan, P. Sengupta, D.C. Webster, High biobased content epoxy-anhydride thermosets from epoxidized sucrose ester of fatty acids, Biomacromolecules, 12 (2011) 2416-2428. [38] E.M. Monono, D.C. Webster, D.P. Wiesenborn, Pilot scale (10 kg) production and characterization of epoxidized sucrose soyate, Industrial Crops and Products, 74 (2015) 987-997. 
[39] A. Paramarta, D.C. Webster, Curing Kinetics of Bio-based Epoxy-Anhydride Thermosets with Zinc Catalyst, Thermochimica Acta (In Revision).

[40] S.G. Tan, W.S. Chow, Thermal Properties, Fracture Toughness and Water Absorption of Epoxy-Palm Oil Blends, Polymer-Plastics Technology and Engineering, 49 (2010) 900-907. [41] S.G. Tan, W.S. Chow, Thermal properties, curing characteristics and water absorption of soybean oil-based thermoset, eXPRESS Polymer Letters, 5 (2011) 480-492.

[42] L.W. Hill, Calculation of crosslink density in short chain networks, Progress in Organic Coatings, 31 (1997) 235-243.

[43] S. Miao, S. Zhang, Z. Su, P. Wang, Chemoenzymatic synthesis of oleic acid-based polyesters for use as highly stable biomaterials, Journal of Polymer Science Part A: Polymer Chemistry, 46 (2008) 4243-4248.

[44] S. Miao, S. Zhang, Z. Su, P. Wang, Synthesis of bio-based polyurethanes from epoxidized soybean oil and isopropanolamine, Journal of Applied Polymer Science, 127 (2013) 1929-1936. 